\title{
GCU
}

Glasgow Caledonian

University

University for the Common Good

\section{Working with and for social enterprises: the role of the volunteer ethnographer}

Hill O'Connor, Clementine; Baker, Rachel

Published in:

Social Enterprise Journal

DOI:

10.1108/SEJ-07-2016-0033

Publication date:

2017

Document Version

Publisher's PDF, also known as Version of record

Link to publication in ResearchOnline

Citation for published version (Harvard):

Hill O'Connor, C \& Baker, R 2017, 'Working with and for social enterprises: the role of the volunteer

ethnographer', Social Enterprise Journal, vol. 13, no. 2, pp. 180-193. https://doi.org/10.1108/SEJ-07-2016-0033

\section{General rights}

Copyright and moral rights for the publications made accessible in the public portal are retained by the authors and/or other copyright owners and it is a condition of accessing publications that users recognise and abide by the legal requirements associated with these rights.

Take down policy

If you believe that this document breaches copyright please view our takedown policy at https://edshare.gcu.ac.uk/id/eprint/5179 for details of how to contact us. 


\section{e emeraldinsight}

\section{Social Enterprise Journal}

Working with and for social enterprises: the role of the volunteer ethnographer

Clementine Hill O'Connor, Rachel Baker,

\section{Article information:}

To cite this document:

Clementine Hill O'Connor, Rachel Baker, (2017) "Working with and for social enterprises: the role of the volunteer ethnographer", Social Enterprise Journal, Vol. 13 Issue: 02, pp.180-193, doi: 10.1108/

SEJ-07-2016-0033

Permanent link to this document:

http://dx.doi.org/10.1108/SEJ-07-2016-0033

Downloaded on: 05 J une 2017, At: 08:29 (PT)

References: this document contains references to 40 other documents.

The fulltext of this document has been downloaded 60 times since 2017*

\section{Users who downloaded this article also downloaded:}

(2017),"Ethnographies of social enterprise", Social Enterprise Journal, Vol. 13 Iss 2 pp. 114-127 http:// dx.doi.org/10.1108/SEJ-03-2017-0019

(2017),"Researcher subjectivity in social entrepreneurship ethnographies: The entanglement of stories in a co-working cooperative for social innovation", Social Enterprise Journal, Vol. 13 Iss 2 pp. 128-143 http://dx.doi.org/10.1108/SEJ-07-2016-0025

Access to this document was granted through an Emerald subscription provided by All users group

\section{For Authors}

If you would like to write for this, or any other Emerald publication, then please use our Emerald for Authors service information about how to choose which publication to write for and submission guidelines are available for all. Please visit www. emeraldinsight.com/authors for more information.

\section{About Emerald www.emeraldinsight.com}

Emerald is a global publisher linking research and practice to the benefit of society. The company manages a portfolio of more than 290 journals and over 2,350 books and book series volumes, as well as providing an extensive range of online products and additional customer resources and services.

Emerald is both COUNTER 4 and TRANSFER compliant. The organization is a partner of the Committee on Publication Ethics (COPE) and also works with Portico and the LOCKSS initiative for digital archive preservation.

*Related content and download information correct at time of download. 
SEJ

13,2

\section{0}

Received 19 July 2016

Revised 16 November 2016

20 January 2017

7 February 2017

Accepted 7 February 2017

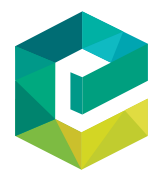

Social Enterprise Journal Vol. 13 No. 2, 2017 pp. 180-193 Emerald Publishing Limited 1750-8614

DOI 10.1108/SEJ-07-2016-0033

\section{Working with and for social enterprises: the role of the volunteer ethnographer}

\author{
Clementine Hill O'Connor and Rachel Baker \\ Yunus Centre for Social Business and Health, Glasgow Caledonian University, \\ Glasgow, UK
}

\begin{abstract}
Purpose - This paper considers the specific opportunities and challenges of engaging in ethnographic research with organisations in which the researcher participates as a volunteer ethnographer.

Design/methodology/approach - The findings in this paper are based on four years of ethnographic research within a social enterprise.

Findings - This paper finds that there are significant benefits of the role of the volunteer ethnographer and suggests ways to address some of the challenges.

Research limitations/implications - As the field of social enterprise and ethnography grows and researchers engage with methodological discussions about participant observation, the authors suggest that attention should also be paid to the specifics of the role of the volunteer ethnographer.

Originality/value - There is growing interest in the use of ethnography in social enterprises. This paper offers unique insight into how this methodology has been applied in the context of self-reliant groups and the importance of the engaging with discussion about the specific role of the volunteer ethnographer.
\end{abstract}

Keywords Ethnography, Volunteer, Social enterprise, Participant observation

Paper type Research Paper

\section{Introduction}

Ethnography is an established methodology that is slowly beginning to enter the field of social enterprise research as researchers become more critically engaged and concerned with in-depth enquiry into the practices and impacts of social enterprises (Mauksch, 2016). Ethnography is distinguished by the use of participant observation alongside other qualitative methods and allows for researchers to share experiences with their research participants to understand and empathise with their world views (Adler and Adler, 1987; Spradley, 1980). This is an important characteristic of ethnography that marks it as a meaningful way to research social enterprise. These types of organisations often include some reliance on volunteers (Amin, 2009) pursuing specific social purposes. Participating side-by-side with such individuals offers new insight into the day-to-day experiences, motivations and challenges of social enterprises. By volunteering, researchers can

(C) Clementine Hill O'Connor and Rachel Baker. Published by Emerald Publishing Limited. This article is published under the Creative Commons Attribution (CC BY 4.0) licence. Anyone may reproduce, distribute, translate and create derivative works of this article (for both commercial and non-commercial purposes), subject to full attribution to the original publication and authors. The full terms of this licence may be seen at http://creativecommons.org/licences/by/4.0/legalcode

This work was supported by the Medical Research Council and the Economic and Social Research Council [grant number MR/L003287/1]. Thanks to colleagues Morag Gillespie, Micaela Mazzei and Cam Donaldson for their contribution to the $\mathrm{PhD}$ research process. 
participate in social enterprises, whilst also "giving back" and contributing to the organisation that has offered access and information. Not only does this role allow for some reciprocity in the research relationship, it also enables a researcher to develop a thick description of social enterprise (Geertz, 2002), as they share in the daily challenges, coping strategies and emotions that are involved in a social enterprise. However, in this environment, ethnographic concerns about the role of the researcher as participant, researcher positioning and reflexivity, negotiating access and even ethical concerns might be even more relevant, given the "participant" in this case is often a "volunteer" working for as well as working with the organisation.

Few articles have dealt with the specific role of the volunteer ethnographer; a term used by Garthwaite (2016) in relation to her research whilst volunteering in a food bank and also discussed by Tinney (2008), who worked as a volunteer within a nursing home. Both authors highlight the role of boundaries that were put in place through the ethics process and the specific working practices of the organisations. Creating such boundaries helped these researchers negotiate between the roles of volunteer and researcher (Tinney, 2008) and discuss the emotional attachment to the field that can lead to feelings of guilt about critically scrutinising those they worked with (Garthwaite, 2016). We argue here that these experiences and arguments are relevant and worthy of discussion in relation to the (so far) limited field of social enterprise and ethnography.

Between 2011 and 2015, one of the authors (C.H.O.) conducted ethnographic research with self-reliant groups (SRGs) in Scotland, and volunteered for WEvolution, the umbrella organisation that initiated SRGs and supports their development. In this paper, we describe the significant value of embodying the role of the volunteer ethnographer participating in the same activities as the research participants and being able to experience the impact of the physical and emotional practice of social enterprises. We also discuss key challenges that arise from this role and relate these to some of the current ethnographic research in social enterprises (Amin, 2009; Dixon and Clifford, 2007; Mauksch, 2016). The discussion is illustrated through field diary excerpts and examples drawn from researching SRGs.

In the sections that follow, we first outline the ways that ethnographic methods have been used in social enterprise research, offering specific in-depth insights and nuanced understanding of this field. We then consider the specific role of the volunteer ethnographer and describe the opportunities and challenges discussed in the existing literature before outlining the context and methods of this study. In the later sections of this paper, we draw on two specific examples from the research, the first of which illustrates the opportunities that are offered by this approach, as the researcher is able to physically and emotionally empathise with those involved in social enterprise. A second example from the research illustrates the specific challenge of managing the demands of the roles of participant/ volunteer-worker and as observer-analyst.

\section{Social enterprise and ethnography}

The common characteristics that connects a wide range of forms and types of social enterprise is a focus on combining social aims and trading activity (Peattie and Morley, 2008; Teasdale, 2011). The variety of forms of social enterprise has resulted in complex and contested narratives and practices which require in-depth analysis to fully understand the field. A common assumption in much of the literature is that they are an organisational form that is an unproblematic way to successfully address various social issues. This dominant narrative has offered only a "utopian rhetoric" of social enterprise (Dey and Steyaert, 2010, p. 85). Ethnography can provide an answer to the dissatisfaction of scholars 
SEJ

13,2

182

in the field who undertake work that is more critically engaged and concerned with "myth busting” (Dey and Steyaert, 2012), giving voice to silenced narratives (Mauksch, 2012) and seeking to address the complexities of social enterprise definitions and practices (Dey and Teasdale, 2015).

As research and researchers become increasingly critically engaged, qualitative, longitudinal methods have proved valuable, which gives some indication of the importance of using methods that can offer a multi-faceted understanding of social enterprise. In a longitudinal study of third sector organisations (including a number of social enterprises), researchers found that relationships with practitioners developed over time and allowed researchers to "uncover the practices and tensions" beneath the formal narratives that were initially given (Taylor et al., 2014, p. 54). In the same study, researchers argued for the need for longitudinal involvement, which shows how views and practices can change over time as well as uses methods that allow researchers to become "part of the powerful performativity of their research subject" (Dey and Teasdale, 2015, p. 501). Using longitudinal qualitative methods allows researchers to analyse some of these underlying practices and tensions, and critically question the apparent coherence suggested by some "snap-shot" case studies of social enterprises as businesses which (un-problematically) pursue social objectives (Pharoah et al., 2004).

Research using ethnography has provided new insights into social enterprise in discussions of the importance of understanding the "emotional value and living meaning" (Mauksch, 2016, p. 17) and helped challenge existing assumptions about social enterprise (Amin, 2009). The longitudinal nature of such work can highlight unexpected outcomes of social enterprise, as in the case of Phillips (2005), when a social entrepreneurship programme in Ukraine did not take into account the socialist history and context. The longer-term outcomes of this project indicate that there is the potential for marginalized groups to be further side-lined, as they are unable to adhere to expectations of a liberalised economy that were the basis of the social enterprise programme that was implemented (Phillips, 2005). Longitudinal ethnographic approaches have also shed light on the shift in narrative over a period as relationships develop and conversations become more "nuanced, multi-faceted, and reflective" (Dey and Teasdale, 2015, p. 491). In a specific case, in Dey and Teasdale's research, the Chief Executive left the organisation during the period of their research, which offered the opportunity for a more open and honest conversation about the strategies undertaken in the organisation "which were initially veiled behind the formal organisational narrative” (Dey and Teasdale, 2015, p. 491). Where research has not been longitudinal, researchers have taken an ethnographic approach using participant observation and walking interviews. This research has produced insights into the importance of the particular context of social enterprises which has implications for the evaluation of such organisations (Munoz et al., 2015).

\section{The role of the volunteer ethnographer}

The prominence given to participant observation within ethnography requires that ethnographic researchers take up the roles of insider and outsider, often performed simultaneously, as the researcher acts as participant and experiences events from within, whilst also being detached and seeking to observe, document and analyse the same event from the perspective of an outsider (Spradley, 1980). As researchers find a balance between these two roles, there are a variety of forms of participant observation they can apply. Finding a balance can be more difficult to manage in the case of volunteer ethnography. A number of typologies have been developed to understand and describe the variety of types of participant observation (Adler and Adler, 1987; Gold, 1958; Spradley, 1980). Broadly they 
can be framed along a continuum, with insider at one end and outsider at the other. Gold (1958) refers to these poles as "complete participant" and "complete observer", the former term is also used by Spradley (1980). Between these two poles, researchers can engage in roles defined as "moderate participation" or "active participation" by Spradley (1980), whilst Adler and Adler (1987) talk in terms of "active membership". Throughout all of these typologies, the concern is with how to manage the level of involvement in the field whilst maintaining a "professional distance that allows adequate observation and recording of data” (Fetterman, 1989, p. 45).

In traditional ethnographies, the levels of participant and observation are the decision of the researchers, who judge these roles based on their own research needs. In the case of volunteer ethnography, the degree of involvement is not the primary decision of the researcher, rather it depends on the organisation, which may have specific demands that the researcher is encouraged to meet. They may be encouraged into particular activities that require higher levels of participation which may restrict time for observation experiences, capturing thoughts and reflections. In Dixon and Clifford's work within a social enterprise addressing environmental issues, there was a pre-existing volunteer relationship with the social enterprise that gave them a high level of access to the organisation. However, it caused difficulties when the role of the volunteer required "too much attention to do justice to the observer role" (Dixon and Clifford, 2007, p. 330). This balance of roles also required management in Mauksch's ethnographic research, in which she reflected on how she had to differentiate between the "participating staff member" and "an at-home analyst" to find the space to be a critically engaged researcher (Mauksch, 2016, p. 9).Taking on the role of the volunteer ethnographer can make it difficult to become a detached observer when volunteering demands commitment as well as emotional and physical labour.

There are a number of ethnographies that explore the role of the volunteers within organisations (Bloom and Kilgore, 2003; Martin, 2014; Portacolone, 2014), but there is a lack of literature that explicitly and critically discusses the role of the volunteer ethnographer. However, Garthwaite (2016) and Tinney (2008) are the exceptions, as both researchers took formal volunteer roles during the course of their fieldwork and discuss this role in detail. In the following discussion, we explore some of the issues they faced in these roles.

Both researchers sought to tackle some immediate ethical considerations in the boundaries they put in place in terms of the specific activities that were prepared to undertake, whether for personal or professional reasons. Garthwaite (2016) chose a Trussell Trust food bank in which to volunteer, as their working practice was to use a referral system rather than make decisions about who they would, or would not, give food aid to. As she was carrying out a volunteer and researcher role, Garthwaite "felt it would be highly unethical" to participate in a form of volunteering that would involve her making judgements about who did or did not receive food aid (Garthwaite, 2016, p. 62). Tinney (2008) also considered the ethics of her involvement as a volunteer and, in negotiation with the management of the care home, agreed to take the role of a "non-care" volunteer, and although she participated in group activities with care home residents, she was not involved in delivering personal care to the residents of the care home she was researching. Had she undertaken these activities, she (and the management of the care home) felt that it would have created a sense of dependency and made it hard for residents to refuse to participate in the research. Whilst she describes some embarrassment when having to refuse requests for help, she was "pleased to have boundaries that kept me from conflating the carer-researcher roles" (Tinney, 2008, p. 220). In drawing these boundaries, Garthwaite and Tinney are engaging in the same negotiation discussed in the literature around the role of participant observer. Both researchers faced ethical dilemmas and made decisions about their roles 
SEJ

13,2

184

based on the idea that as researchers there are specific activities that should not be engaged in. These decisions highlight the importance of negotiating roles when researchers are participating in volunteering activity in which they are considered "insiders" and "participants" but also have responsibilities to the research process.

Negotiating and shifting roles is a familiar part of the ethnographic research experience, as discussed previously; when the role is part of a more formal volunteer contract, this becomes more difficult. Demands can be placed on the volunteer ethnographer because of the formal commitment that has been made to an organisation. Garthwaite made the decision to call herself a "volunteer ethnographer" rather than an "ethnographic volunteer" because the users of the food bank saw her, first and foremost, as a volunteer. However, she also acknowledges that she was only volunteering because she was conducting ethnographic fieldwork and so it was difficult to decide how to describe herself, but settled on volunteer ethnographer. We would suggest that, like the change in nature of participant observation or the shift between insider-outsider status, the emphasis changes depending on the stage of the fieldwork. Garthwaite (2016) describes working around the needs of the food bank and changing her plan of what day she would commit to be a volunteer. In this regard, her focus was on the volunteer role, as she built trust and rapport with the organisation and service users to build relationships "not solely focused on the researchers' needs and objectives" (Garthwaite, 2016, p. 63). Tinney (2008) also emphasises the importance and value of the role of the volunteer for the quality of insight she gained. She also notes that in an organisation in which the staff members were often stretched to capacity, she was viewed as an extra resource and participation, rather than observation, became more consuming.

As the research progresses, it is important to refocus on the research and, as found in Mauksch's work, to find space away from the field to be a researcher, first and foremost. Tinney also recognised this concern in the field and through distinguishing herself as a "non-care volunteer", she attempted to limit some of her participation to "preserve enough distance to meet the responsibilities entailed in ethical and rigorous research" (Tinney, 2008, p. 207). This may require applying a critical framework to people with whom researchers have built relationships, as in the case of Garthwaite (2016). She describes feelings of guilt during the analytic process, though she maintained relationships and provided feedback on her research to those she volunteered alongside. This is as compared to Tinney's work, in which she is a self-proclaimed advocate of the residents and staff of the care homes she researched (Tinney, 2008). However, in both cases, the researchers emphasise the work and relationships that continued after the formal involvement as volunteer ethnographers. Although Garthwaite felt guilt during the analytical stages of the research, she reports no negative feedback from the food bank and states that she feels it is "vital" to remain connected to the field in order "not to just completely dissolve the close relationships" (Garthwaite, 2016, p. 68) that formed in the field.

At the heart of the issues facing volunteer ethnographers is the fact that, like organisational ethnographers, they "leave their work in the university and go and work in a second organisation (Gilmore and Kenny, 2015, p. 70). The difficulties arising from this are amplified in the case of volunteer ethnographers who have formalised their roles within a second organisation and may have additional commitments and levels of guilt and internal conflict as their research and their research relationships develop. Building on existing work, we consider how the roles discussed by Tinney and Garthwaite can be applied to the field of social enterprise using examples from the doctoral research of one of the authors (C.H.O.). Whilst the examples above tend to focus on the challenges faced by researchers taking on the role of the volunteer ethnographer, we want to highlight the value and 
insight that can be realised by embodying the role of the volunteer ethnographer in social enterprise research. Through lived experience, researchers benefit from insights and understandings of those involved in social enterprises - not only the informal, or behind the scenes conversations but also the everyday physical and emotional practice of involvement in a social enterprise. However, as highlighted in the previous discussion, one of the key challenges in taking this research approach is managing the demands of both roles, as participant/volunteer-worker and as observer-analyst, when those roles pull in different directions. We discuss how this challenge was managed throughout the doctoral research.

\section{Volunteer ethnography in self-reliant groups}

This research began in 2011 when a group of 13 women from 7 low-income communities in Scotland were funded by an organisation to travel to India to learn about self-help groups (SHGs). Influenced by meetings with Indian SHG members, women from Scotland were inspired to start similar groups in their own communities and supported by the organisation to do so. SHGs bring women in India together to provide peer support and financial benefits for individuals, their families and communities. Indian SHGs have resulted in increased income which has given women economic power and enhanced their ability to address social problems in their communities. There have been a number of discussions around the efficacy of SHGs with regards to women's empowerment (Hunt and Kasynathan, 2001; Leach and Sitaram, 2002; Mayoux, 1998, 1999) and some critique of the model more generally (Pattenden, 2010). Nevertheless, there is also significant evidence to indicate that in some parts of India, SHGs have effectively challenged issues around access to medical care, agricultural management, education, women's empowerment and political participation (Bali and Wallentin, 2009; Khatibi and Indira, 2011; Mohindra et al., 2008; Tesoriero, 2006). In Scotland, women from similar socio-economic backgrounds have organised themselves, into groups of between five and ten, meeting and saving small amounts of money on a weekly basis. The groups have been renamed self-reliant groups (SRGs) because there were some misunderstandings about the nature of the groups, as the term self-help group was felt to have connotations of addiction support groups. WEvolution developed in parallel to the SRGs and formulated support mechanisms in response to requests from SRGs. As income generation emerged as a key aim for the women in the SRGs, they started to consider how to build their own businesses and the organisation began fund-raising for a microfinance scheme for the groups.

The aim of all of the current SRGs is to start a business, while retaining the core ethos, which focuses on the collective. The groups provide valuable peer support to women and they aim to find a balance between social and economic outcomes. The role of WEvolution is to act as a facilitator to groups, providing key training opportunities for group development, linking groups to business mentors and offering small loans to groups once they get to the stage of forming businesses. SRGs and WEvolution that supports them fit the (broadest) definition of social enterprise in a number of ways. The businesses set up by SRGs have been established as community interest companies (CICs), a common legal form for social enterprises in the UK. It is also possible to see the way that the collective ethos of the businesses SRGs seek to develop build on co-operative and mutual ideals that guides some concepts of social enterprises (Defourny and Nyssens, 2010; Pearce, 2003). C.H.O. volunteered in both settings. and this paper draws on evidence from WEvolution and the SRGs in order to comment on the application of ethnography across a variety of types of social enterprise.

\section{Role of the volunteer ethnographer}


SEJ

13,2

186

\section{Methods}

Our involvement in the project began prior to the initial trip to India, when C.H.O. was employed as a temporary intern to capture the experiences of the 13 women participating on the trip. Our research team remained involved as they returned and C.H.O. began to attend planning meetings and social events with the group and eventually made the organisation the subject of her doctoral study. There was significant enthusiasm and support from the organisation that recognised the value of having a researcher connected to their work. They supported the idea that C.H.O. would act as a type of "critical friend" as the organisation developed (Rallis and Rossman, 2000). C.H.O. was encouraged to ask provocative questions and was asked for feedback about the working practices of WEvolution. In her involvement in the SHGs, C.H.O. was able to participate in day-to-day experiences, which gave her insight into the organisational working practices of SRGs and how involvement was impacting (or not) on other areas of their lives. This type of long-term, in-depth involvement meant an opportunity to break down some of the barriers between researcher and researched (Dey and Teasdale, 2015). In the following sections, we use pseudonyms for all the research participants but we have not used a pseudonym for WEvolution, given their profile and specificities of their model, the organisation is familiar and recognisable to people in the field.

Over a period of three years, and 18 months of fieldwork, the research focussed on two SRGs (that emerged from the efforts of the women who initially visited India) and on the developing organisation. The PhD-student-researcher-volunteer was involved in SRG meetings, organisational meetings and attended a variety of formal and informal events related to SRGs and WEvolution numbering over 30 formal team meetings within the organisation and over 60 SRG meetings. Working across three field sites, namely, Edgeburn SRG, Whitehurst SRG and WEvolution, the researcher C.H.O. inhabited a range of roles and continuously reflected on the position of insider and outsider. In both settings, she was able to act in a volunteer-type role and take on specific tasks and responsibilities; accepted as an "insider" to a certain extent. The limited staffing capacity during the early stages of the research meant there were times when the researcher was asked to facilitate meetings, attend or organise certain events and represent the organisation to other groups, including potential funders. In other meetings, she took a more observational role. This work yielded significant insights into the development of the organisation over time, the rationale for various strategic decisions and the relationship between the WEvolution and the SRGs. Participation in the SRGs was encouraged by the members of the group. C.H.O. joined them in skills development training, learned how to use a sewing machine with Edgeburn SRG and helped make sandwiches, serve soup and clear the dishes in Whitehurst SRG. C.H.O. was quickly accepted as one of the group and felt welcome and included throughout her time in the field. The rapport that she developed also allowed her into some of the more difficult discussions in the SRGs, for example when Edgeburn SRG members were grappling with how to address the issue of non-attendance and how it was affecting the morale of the group.

There were significant advantages and challenges in negotiating different roles, which we describe and discuss in the following sections. Using an excerpt from fieldnotes, we illustrate an experience in which the importance of the role of the volunteer ethnographer was made clear. In embodying the physical practices of the SRG members, C.H.O. was able to feel the emotional impacts of the activities that previously had only been described to her. We then draw on further examples from fieldnotes and consider the difficulties when disagreements arose, which took time and energy away from the research aspect of the role. 


\section{Empathetic involvement - an opportunity for volunteer ethnographers}

Whitehurst SRG was the first group to emerge from the trip to India in 2011; they began meeting in March 2011 and though there have been some changes in membership, a core of five members has remained consistent. The SRG members had observed a lack of social opportunities for the pensioners in their neighbourhood and began a weekly lunch club in the local church. The following passage is an excerpt from C.H.O.'s field diary, in which she recounts an experience which illustrates the value of participating as a volunteer within a social enterprise. C.H.O. had been meeting with the SRG for two years at the point of this visit and had become part of the "lunch club team":

After a horrible night of tossing and turning and worrying about the presentation I have to do next week I woke up to find out I'm even more overdrawn than I thought and need to cancel my plans this weekend. As I travelled in to spend the afternoon with Whitehurst SRG I focused on the need to push all that to one side, but knew that I'd struggle not to worry about the bank charges I faced and the fact that I knew I'd have to let a friend down and cancel my trip to see her. Nevertheless I put on my fieldworker face and tried to get on with the task at hand, research into the experiences of women involved in SRGs. Once I arrived I quickly fell into the routine of the SRG; a catch up over tea, coffee and plenty of biscuits. This week Sarah had been looking after her grandchildren so had lots to tell us, then some of the women reminisced about their own childhoods and I got to hear about what this neighbourhood had been like to grow up in. Then we headed to the kitchen and I helped Jo with the sandwiches while the others laid the tables and set out the bingo machine and prizes. At 12 o'clock the first lunch clubbers arrived and the hall quickly filled up while I helped dish up bowls of soup and plates of sandwiches from the orders shouted through the serving hatch in the kitchen. It went quiet, as it always does, as the bingo started; Rebecca was in charge of calling while others helped some of the lunch clubbers to fill in their cards and someone presented the various prizes. Jo closed the hatch between the kitchen and the hall while the rest of us quietly dealt with the washing up. I was halfway through my designated stack of dishes and plates when I realised I had a big smile on my face and had not worried about my overdraft for several hours now. Rather than feeling like a failure who can't handle her money I'd had a great morning chatting to Sarah, Jo and the others followed by an afternoon of practical and useful work. The women in Edgeburn and in Whitehurst had told me that they valued the SRG as a chance to get out of the house and do something useful and this was the first time I had really appreciated what they meant by these comments. I knew my issues were trivial in comparison to what I knew some of the other women were facing but I gained an important first-hand experience of just how powerful the SRG experience could be in giving women time and space away from the difficult bits of their lives.

Conducting interviews and initiating informal conversations had raised the question of the value of SRGs in terms of women doing something productive and useful. They described this as a distraction, or space away, from the difficulties and boredom they experienced in other areas of their lives. Charlie, from Edgeburn SRG, put this clearly when she said during the course of an interview:

While I'm here I can focus on the work rather than what's going on in my mind. Because if I was sitting in the house l'd be going crazy thinking about stuff. So it does take your mind off stuff and gives you something to focus on (Charlie, October 2014).

The direct experience of the focus and distraction of SRG activity was only possible to achieve through the ethnographic fieldwork and inhabiting aspects of the same role as the SRG members, as a volunteer ethnographer. It offered a "lightbulb moment" of realisation that aided the analysis and understanding of the SRGs. Goffman has called for fieldwork that involves:

\section{Role of the volunteer ethnographer}


SEJ

13,2

[...] subjecting yourself, your own body and your own personality, and your own social situation to a set of contingencies that play on a set of individuals, so that you can physically and ecologically penetrate their circle of response to their social situation, or their work situation (Goffman, 1989, p. 125).

This important experience led to considerations about what was happening in the home that women feel they want to get away from. The focus on productivity led to questions about the other areas of women's lives where they may or may not feel productive and why their valuable roles as mothers and carers were not enough for them. In line with the cyclical nature of ethnography, which requires examination of details and then pulling away to analyse details within a wider context, the researcher began to explore the bigger picture, and the day-to-day experiences of women's lives. It was found that home represented being dependent on social security payments and a sense of passivity, waiting for the next payment and often living in fear of the "brown envelope" (Garthwaite, 2014) that would inform women of the outcome of various appeals regarding the bedroom tax or sanctions. The same negative rhetoric and stereotypes of the unemployed that made commitment and SRG membership valuable encroaches into the private space of the home, make women feel useless, and turn the home into a negative space that they feel the need to escape. Physical involvement in the SRG activities strengthened our understanding of the impact of involvement in the group, as it allowed C.H.O. to be empathetic (Goffman, 1989). The specific circumstances of C.H.O.'s life at that time had led to a certain set of emotions, and there was recognition of huge value of activities that helped to distract from that. It forced a more in-depth analysis of what was happening in women's lives, which meant that the time away from home was so highly valued.

The decision to take the role of the volunteer ethnographer in this setting was partly a specific choice, as in the case of Tinney (2008) and Garthwaite (2016), because C.H.O. wanted to be useful to those she was researching. Rather than observe as an outsider, as well as expect women to take time away from their activities for more formal interviews, C.H.O. chose to participate to build trust and understanding. A significant benefit of this was that it allowed for direct experience and it was possible for the researcher to physically and emotionally empathise with the impacts the SRG members described in interviews.

\section{Working with or working for? - Challenges for volunteer ethnographers}

Managing emotions and relationships with colleagues in the field is a difficult process, as researchers can experience a sense of collegiate warmth and friendship. This can then lead to a level of guilt for researchers when have to turn their critical lens onto groups and individuals they have worked alongside in this way (Garthwaite, 2016; Gilmore and Kenny, 2015). Other interactions can be less positive and also have implications for the researcher. Mauksch (2016) describes a "disgruntled" colleague who reacted badly to a question about some of the core beliefs held by Muhammad Yunus, the figurehead of the social enterprise she was working. An issue that was encountered during this research related to specific times when there was a sense of annoyance or frustration with colleagues in the field. C.H.O. found occasions when she felt a sense of resentment in being asked to do certain jobs which led to an imbalance, from her perspective, between the roles of researcher and volunteer.

The umbrella organisation had arranged a meeting with a senior civil servant who would visit one of the SRGs and spend time discussing the difficulties they were facing within the social security system. At this time, a key issue that was emerging 
from the research related to the ways that SRG members were engaging with the social security system, as they reported both positive and negative reactions from the Job Centre Plus when they described their involvement in the groups. As a volunteer, C.H.O. had also taken on the responsibility of delivering talks about SRGs, and about the research, to organisations who were interested in fund-raising for the microfinance scheme to support SRG business development. C.H.O. was also helping the SRG development worker, Beth, organise a training event for some of the SRG members. In the following excerpt from fieldnotes, the frustration of trying to balance various roles is clear, as volunteer responsibilities began to conflict with aspects of the researcher role:

The event with the civil servant was on the agenda at the team meeting again today, Beth and David are working to agree an agenda. I'm still frustrated that I am unable to go because of the talk that David needs me to give. Observing the meeting between the SRGs and the civil servant seems like such a good opportunity to see the groups interacting with a totally different group of people, and might shed more light on some of the social security related issues that seem to be a theme at the moment. Unfortunately, I'll be missing out on this to be a staff member for David, talk about blurred boundaries! Hearing them talk about the plans for the meeting put me in a bad mood and so I went on the defensive when he asked Beth and me to talk through the rationale for the training event that we are trying to organise. We have been through it several times and it feels like he is checking up on us. I think perhaps I am being grumpy and a bit unfair on David. What it all comes down to is that I am starting to feel like rather than working with the organisation I am working for the organisation and being predominantly a volunteer rather than a researcher.

In this exchange, there is a sense of frustration with the situation and for showing these emotions when it was in the interests of C.H.O. to "maintain difficult relations during fieldwork, even if those relations become strained or difficult" (Coffey, 1999, p. 55). We suggest that the likelihood of strained relationships is heightened in the situations in which the researcher takes dual role that includes some form of volunteering. Coffey argues that relationships in the field can be difficult when all those involved "see the field and the relation of the field as work" (Coffey, 1999, p. 55).

After this interaction, C.H.O. sought to find a way to rebalance the roles and discussed a more formal differentiation of roles. C.H.O. had started volunteering, partly due to the lack of capacity within WEvolution, which had enabled access and the organisation, as C.H.O. was another resource they could draw on. However, the agreement of the role was never formalised, as in the case of other volunteers who might undergo specific training (Garthwaite, 2016) or take on jobs that allowed for more observation (Dixon and Clifford, 2007). David and C.H.O. met and agreed that while she was happy to play a part in organising and planning events not directly related to the research process, it was important that these were not activities that were in direct conflict with research priorities. It was a difficult conversation to have, but it was important to recognise the value of maintaining a good relationship and acknowledge the unique insights C.H.O. had gained through David trusting her to be involved at the level of other volunteers and employees. C.H.O. and David also tried to work through the issue of dual roles of participant and observer, volunteer and ethnographer, and considered the situations in which C.H.O. was one or both of these roles to differentiate between the roles.

The discussion David and C.H.O. had, and the agreement that was made, was part of an ongoing dialogue which ran throughout the course of the fieldwork. As a research partner, with an interest in the outcome of the research, he was also committed to retaining a good working relationship and these continuing conversations were of benefit 
SEJ

13,2

to both parties as they navigated through the research process. The exchange required honesty and transparency in relation to the expectations, for the research and the different roles that C.H.O. was taking on. This solution also helped to address the concerns that Garthwaite (2016) highlights regarding a researcher's feeling of guilt during this type of research. A sense of betrayal can also arise within the organisation and research participants (Beech et al., 2009), and this level of transparency helped manage this. As in the case of Tinney (2008) and Garthwaite (2016), there was a need for official lines that differentiated the role of the volunteer from the role of the researcher, which led to a level of formalisation. Unlike someone participating in paid work or volunteering for WEvolution, it was agreed that there were different sets of priorities in many cases and C.H.O. had to be able to refuse to take part in certain activities should they prove to conflict with the research priorities.

\section{Conclusion}

Volunteering roles in organisations give the chance for researchers to become "volunteer ethnographers" and directly participate in the physical and emotional experiences of the phenomena that are being researched. There are a number of examples of this within the limited literature on social enterprises using ethnographic methods, and we have drawn on these examples and considered the challenges and opportunities in more depth. We contribute to the growing interest in ethnography and social enterprise, drawing attention to the issues facing researchers in this specific context. In doing so, we have offered examples of situations that should be considered when researchers contemplate the use of ethnography in social enterprise research.

The illustrations we have presented here have developed three key insights into the role of the volunteer ethnographer. In the first case, we use an excerpt from the field diary of the researcher-volunteer involved in fieldwork with SRGs and the supporting umbrella organisation to illustrate how C.H.O. was able to engage in the same activities as the women in the SRGs. We show that the role helped develop empathy with the research participants, which led to an explanation of the motivation and commitment to the SRGs and the value they ascribed to their involvement. Secondly, we illustrate a challenge that C.H.O. faced in which there was a sense of failing in both the role of the volunteer and the researcher. C.H.O. described some of the difficult emotions that arose when in the role of the volunteer ethnographer. In this research, C.H.O. was able to manage these through ongoing discussions with David to negotiate the role more openly. The decision to formalise the volunteer role to distinguish between volunteer and ethnographer reflects some of the boundaries that Tinney put in place as she carried out her research. However, she also discussed the shifting nature of this boundary and thus the importance of the type of ongoing discussions C.H.O. and David embarked on after the specific conflict between volunteer and ethnographer roles. This active negotiation illustrates the need for honesty and transparency in the field to be able to fulfil both roles with more rigour.

Each experience of ethnography will be unique, and a one-size-fits-all model is not appropriate for this type of research. Nevertheless, there is an existing body of work that explores the various roles that a researcher might play. As the field of social enterprise and ethnography grows and researchers recognise the methodological history of participant observation, we suggest that attention should also be paid to the specifics of the role of the volunteer ethnographer. There are also a number of limitations of this dual role to be considered as researchers decide what approach they intend to take. In C.H.O.'s position, she was able to volunteer in two settings, as an SRG member and as a member of WEvolution, which offered two different perspectives on the social enterprise. In other contexts, taking on 
the role of the volunteer may limit the access and insight into other aspects of the organisation. There are practical considerations that are important, as commitments beyond that of volunteer may take precedence, as it did in the example in this paper. Whilst C.H.O. was able to openly negotiate with the organisation with regards to the nature of the different roles, it may be the case for researchers unable to commit to the role of the volunteer, for research or other reasons; they may lose their access to the research site or to particular individuals. We mention these to further open up the discussion and pose questions and challenges that we have begun to address in this paper. It is hoped that from this paper, there will be more contributions to the debates about roles in the field, and how these can further our understanding of the social enterprise sector.

\section{References}

Adler, P. and Adler, P. (1987), Membership Roles in Field Research: Qualitative Research Methods Series 6 , SAGE, London.

Amin, A. (2009), "Extraordinarily ordinary: working in the social economy", Social Enterprise Iournal, Vol. 5 No. 1, pp. 30-49.

Bali, S.R. and Wallentin, F.Y. (2009), "Does microfinance empower women? Evidence from self-help groups in India", International Review of A thlied Economics, Vol. 23 No. 5, pp. 541-556.

Beech, N., Hibbert, P., MacIntosh, R. and McInnes, R. (2009), "But I thought we were friends? Life cycles and research relationships", in Ybema, S., Yanow D., Wels F. and Kamsteeg, F. (Eds), Organizational Ethnography: Studying the Complexities of Everyday Life, SAGE Publications, London.

Bloom, L.R. and Kilgore, D. (2003), "The volunteer citizen after welfare reform in the United states: an ethnographic study of volunteerism in action", Voluntas: International Iournal of Voluntary and Nonprofit Organizations, Vol. 14 No. 4, pp. 431-454.

Coffey, A. (1999), The Ethnographic Self: Fieldwork and the Representation of Identitv, Sage, Thousand Oaks, California, CA.

Defourny, J. and Nyssens, M. (2010), "Conceptions of social enterprise and social entrepreneurship in Europe and the United states: convergences and differences", Lournal of Social Entrepreneurship, Vol. 1 No. 1, pp. 32-53.

Dey, P. and Steyaert, C. (2010), "The politics of narrating social entrepreneurship", Lournal of Enterprising Communities: People and Places in the Global Economv, Vol. 4 No. 1, pp. 85-108.

Dey, P. and Steyaert, C. (2012), "Social entrepreneurship: critique and the radical enactment of the social", Social Enterprise Iournal, Vol. 8 No. 2, pp. 90-107.

Dey, P. and Teasdale, S. (2015), "The tactical mimicry of social enterprise strategies: acting 'as if' in the everyday life of third sector organizations", Organization, Vol. 10 No. 4, doi: 1350508415570689.

Dixon, S. and Clifford, A. (2007), "Ecopreneurship - a new approach to managing the triple bottom line", Journal of Organizational Change Management, Vol. 20 No. 3, pp. 326-345.

Fetterman, D. (1989), Ethnography: Step by Step, Sage, Thousand Oaks, California, CA.

Garthwaite, K. (2014), "Fear of the brown envelope: exploring welfare reform with long-term sickness benefits recipients", Social Policy \& Administration, Vol. 48 No. 7, pp. 782-798.

Garthwaite, K. (2016), "The perfect fit? Being both volunteer and ethnographer in a UK foodbank", Lournal of Organizational Ethnographv, Vol. 5 No. 1, pp. 60-71.

Geertz, C. (2002), "Thick description: toward an interpretive theory of culture", The Interpretation of Cultures, available at: www.brookechornyak.com/files/thick-description.pdf (accessed 22 August 2014).

\section{Role of the volunteer ethnographer}


SEJ

13,2

Gilmore, S. and Kenny, K. (2015), "Work-worlds colliding: self-reflexivity, power and emotion in organizational ethnography”, Human Relations, Vol. 18 No. 2.

Goffman, E. (1989), "On fieldwork”, Lournal of Contemporary Ethnography, Vol. 18 No. 2, pp. 123-132.

Gold, R.L. (1958), "Roles in sociological field observations”, Social Forces, Vol. 36 No. 3, pp. 217-223.

Hunt, J. and Kasynathan, N. (2001), "Pathways to empowerment? reflections on microfinance and transformation in gender relations in South Asia", Gender \& Development, Vol. 9 No. 1, pp. $42-52$.

Khatibi, F.S. and Indira, M. (2011), "Empowerment of women through self help groups and environmental management: experiences of NGOs in Karnataka state, India", Journal of Human Ecology, 34(1), 29-40.

Leach, F. and Sitaram, S. (2002), "Microfinance and women's empowerment: a lesson from India", Development in Practice, Vol. 12 No. 5, pp. 575-588.

Martin, N. (2014), "Spaces of hidden labor: migrant women and work in nonprofit organizations", Gender. Place \& Culture, Vol. 21 No. 1, pp. 17-34.

Mauksch, S. (2012), "Beyond managerial rationality: exploring social enterprise in Germany", $\underline{\text { Social }}$ Enterprise Iournal, Vol. 8 No. 2, pp. 156-170.

Mauksch, S. (2016), "Managing the dance of enchantment: an ethnography of social entrepreneurship events", Organization, Vol. 24 No. 2, doi: 1350508416644511.

Mayoux, L. (1998), "Women's empowerment and micro-finance programmes: strategies for increasing impact”, Development in Practice, Vol. 8 No. 2, pp. 235-241.

Mayoux, L. (1999), "Questioning virtuous spirals: micro-finance and women's empowerment in Africa", Lournal of International Development, Vol. 11 No. 7, pp. 957-984.

Mohindra, K., Haddad, S. and Narayana, D. (2008), "Can microcredit help improve the health of poor women? Some findings from a cross-sectional study in Kerala, India”, International Iournal for Equitv in Health, Vol. 7 No. 1, p. 2.

Munoz, S.-A., Farmer, J., Winterton, R. and Barraket, J. (2015), "The social enterprise as a space of wellbeing: an exploratory case study", Social Enterprise Iournal, Vol. 11 No. 3, pp. 281-302.

Pattenden, J. (2010), "A neoliberalisation of civil society? Self-help groups and the labouring class poor in rural South India”, Journal of Peasant Studies, Vol. 37 No. 3, pp. 485-512.

Pearce, J. (2003), Social Enterprise in Anytown, Calouste Gulbenkian Foundation, London.

Peattie, K. and Morley, A. (2008), Social Enterprises: Diversity and Dynamics, Contexts and Contributions, Social Enterprise Coalition, London.

Pharoah, C., Scott, D. and Fisher, A. (2004), Social Enterprise in the Balance, Charities Aid Foundation, West Malling.

Phillips, S.D. (2005), "Will the market set them free? Women, NGOs and social enterprise in Ukraine", Human Organization, Vol. 64 No. 3, pp. 251-264.

Portacolone, E. (2014), "Older Americans living alone the influence of resources and intergenerational integration on inequality", Iournal of Contemporary Ethnography, Vol. 44 No. 3, doi: 0891241614528709 .

Rallis, S.F. and Rossman, G.B. (2000), "Dialogue for learning: evaluator as critical friend", $\underline{\text { New }}$ Directions for Evaluation, Vol. 2000 No. 86, pp. 81-92.

Spradley, J.P. (1980), Participant Observation, Holt, Rinhart and Winston, New York, NY.

Taylor, R., Arvidson, M., Macmillan, R., Soteri-Proctor, A. and Teasdale, S. (2014), "What's in it for us? Consent, Access, and the meaning of research in a qualitative longitudinal study", in Camfield, L. (Eds), Methodological Challenges and New Approaches to Research in International Development, Palgrave Macmillan, Basingstoke. 
Teasdale, S. (2011), "What's in a name? Making sense of social enterprise discourse”, Public Policy and Administration, Vol. 27 No. 2, pp. 99-119.

Tesoriero, F. (2006), "Strengthening communities through women's self help groups in south India", Communitv Develobment Iournal, Vol. 41 No. 3, pp. 321-333.

Tinney, J. (2008), "Negotiating boundaries and roles: challenges faced by the nursing home ethnographer", Journal of Contemporarv Ethnograbhv, Vol. 37 No. 2, pp. 202-225.

Corresponding author

Clementine Hill O'Connor can be contacted at: clementine.hilloconnor@gcu.ac.uk

For instructions on how to order reprints of this article, please visit our website: www.emeraldgrouppublishing.com/licensing/reprints.htm Or contact us for further details: permissions@emeraldinsight.com 